\title{
Opinions About Mental Illness Among Primary School Teacher Trainees in Kenya
}

\author{
Eunice Jemalel Nyavanga ${ }^{1, *}$, Maurice Barasa ${ }^{2}$ \\ ${ }^{1}$ The Technical University of Kenya, Faculty of Social Sciences and Technology, School of Social and Development Studies, and Department \\ of Human and Social Development, Kenya, Nairobi \\ ${ }^{2}$ Health Information Systems Advisor, The MDG Centre of Columbia Global Centre, Nairobi, Kenya
}

Email address:

enyavanga@yahoo.com (E. J. Nyavanga),barazam@gmail.com (M. Barasa)

${ }^{*}$ Corresponding author

\section{To cite this article:}

Eunice Jemalel Nyavanga, Maurice Barasa. Opinions About Mental Illness Among Primary School Teacher Trainees in Kenya. Psychology and Behavioral Sciences. Vol. 5, No. 3, 2016, pp. 62-68. doi: 10.11648/j.pbs.20160503.11

Received: May 2, 2016; Accepted: May 20, 2016; Published: June 1, 2016

\begin{abstract}
This study aimed to determine and document the opinions about mental illness among public primary teacher trainees in Kenya. Convenience sampling was used to identify four public teacher colleges out of the twenty. Self-administered demographic questionnaire and opinions about mental illness scale were presented to the participants to collect data. The OMI consisted of five factors of authoritarianism, benevolence, social restrictiveness, mental hygiene ideology and interpersonal etiology. Ethical protocol was followed from getting authority to informed consent from the participants. Out of the 2925 questionnaires presented, 2777 were returned fully filled, a return rate of $94.34 \%$. Summative scores indicated moderate towards more negative opinions about mental illness, with significant differences in year of study, gender, marital status, or ever taught before coming to college. There was a correlation between all the OMI factors. This study found negative opinions about mental illness among these participants and recommended on an intervention in order to improve attitudes towards help in seeking help.
\end{abstract}

Keywords: Mental Illness, Opinions, Teacher Trainees

\section{Introduction}

According to World Health Organization (WHO) [1] an estimated 450 million people suffer from mental illness worldwide; and one person out of four persons will develop one or more of these mental illnesses during their lifetime. These conditions account for $13 \%$ or the total Disability Adjusted Life Years (DALYs) lost due to all diseases and injuries. It has also been estimated to increase to $15 \%$ by the year 2020 [1].

Mental health Systems in many countries, Kenya included is seriously under-developed [2] yet five leading causes of disability worldwide are psychiatric conditions. Research has shown that depression, substance abuse, physical abuse and sexual abuse as the new morbidities of the youth [3]. According to Tinsley et al, [4], negative opinions towards mental illness is particularly important because behavioural problems are replacing infectious diseases as the major cause of morbidity and mortality among young adults.

A study by SCAD, (unpublished) done in Kenya on the perceptions of mental disorders by Kenyan youth indicated that mental illness exist among the youth as well as the general population which has an attached stigma and causes being availability of drugs and witchcraft among others.

Studies on the prevalence of psychiatric morbidity among teachers have found higher percentages than that of the general population $[5,6,7,8]$. It has been suggested that schoolteachers are exposed to highly stressful situations, which are related to psychological and psychiatric problems among Australian and Scottish teachers, [7]. Teacher stress affects the learning environment and interferes with the achievement of education goals as it may lead to a teacher's detachment, alienation, absenteeism, and ultimately the decision to leave the profession, [7]. 


\section{Main Body}

\subsection{Importance of Opinions of Mental Illness to Teachers}

The role of opinions in mental illness plays a great role in teaching in primary schools. Negative opinions might present barriers to identifying mentally ill children or other teachers in a school. The impact of opinions of mental illness among teachers in a primary school may enhance or destroy the potential to the mentally ill persons. Teachers are role models to pupils and stand in unique positions to pupils that set values of mental health issues, [8]. Understanding their opinions would go a long way to assist in identifying not only their mental health issues but also for their pupils.

\subsection{Public Primary Teacher Training in Kenya}

Public primary teacher training in Kenya is made up of 20 colleges with an enrolment of an estimate of 17,868 trainees [9]. The Ministry of Education, (Department of Statistics), estimates that the total capacity out per year for primary school teachers is between 8,000 to 10,000 teachers [9]. The training normally takes two years and at the end they all take one common examination by the Kenya National Examination Council (KNEC), before they can graduate with a Teaching Certificate [9].

\subsection{Justifications and Significance of the Study}

In a prevalence survey study of Psychiatric Morbidity among primary public school teachers, [5], it was found out that $41.3 \%$ of teachers in Mogotio Division, Koibatek District, Kenya have at least one mental illness. These illnesses do not seem to have had any treatment, most properly because of the teachers perceptions of the illness. This study aims to determine and document the opinions of mental illness among public primary teacher trainees in Kenya. This will fill the gap of knowledge lacking in this area, and develop an intervention that would help them seek help as there is no such study done in Kenya and very few done in Africa.

The American Psychiatric Association (APA) [10] indicated that young adults have the greatest risk for the onset of many major mental illnesses, which include schizophrenia, bipolar, major depression, anxiety disorders, and substance abuse Trainee teachers are young adults and fall in this category of onset. Opinions about mental illness influence attitudes towards help seeking. Research has also indicated a correlation between Opinions of Mental illness, help seeking behaviour and psychotherapy and counseling, [4].

The United Nations general Assembly of $25^{\text {th }}$ September 2015 included mental health in the United Nations Sustainable Development Goals (SDG) aimed to be achieved transform the world by 2030, [11]. This aims to promote mental health and well being, the prevention and treatment of substance abuse. To achieve this research is important in identifying opinions of mental illness in order to develop better ways in prevention, diagnosis and treatment.

\section{Methodology and Study Design}

\subsection{Methods}

\subsubsection{Settings and Study Population}

This study utilized the convenience sampling method to identify the colleges for research. This method was deemed appropriate for this research since it is known to save transport costs, time and efforts. It was also established that these trainees were recruited from all over the country using a quota system. Four public primary teacher trainee colleges were sampled conveniently out of 20 colleges found in Kenya. Based on lists from the Ministry of Education enrolment (Statistics Department) the effective population for the study was estimated at 3, 400 (out of 17,000) trainees from the sampled colleges. The colleges sampled were Kilimambogo, Murang'a, Thogoto and Machakos. This study is part of a larger longitudinal quasi-experimental (intervention) study; "The Effects of Psychoeducation on Attitudes towards Mental Health seeking Behaviour among Students of Primary School Teachers in Training Colleges in Kenya”.

All consenting participants from the identified colleges were recruited for the study to increase the generalizeability of the findings. The authors assumed that primary teacher trainees would understand the working in the Opinions about Mental Illness scale (OMI) and would be honest and accurate in their responses to the questionnaire.

2,925 questionnaires were presented to the participants, and 2,759 were returned fully filled, a response rate of $94.32 \%$.

\subsubsection{Ethical Considerations}

The Kenyatta National Hospital Ethics Committee (KNHEC) protocol, which sets forth research ethics concerning individual's data in Kenya, was strictly followed to ensure confidentiality. The researcher obtained KNH-EC approval and clearance prior the study. The researchers got authority from the Ministry of Education (Research Department) before conducting the District Commissioner and the District Education Officers with a clear explanation on the purpose, plan, and implications of the study, before seeking their assistance with arrangement on how and when to distribute the questionnaires. The researchers also explained the same to the College administration and written consent was obtained. The participants were met in their different classes and the purpose, plan and implications of the study were explained to them. They were also informed participation was voluntary.

\subsubsection{Study Procedures and Instrumentation}

The participants were met by the trained Psychologists, and assisted to answer the questionnaires into an answer sheet in their respective classes. The present research is directed at clarifying the opinions public primary teacher trainees on mental illness. The participants were asked to fill in a demographic questionnaire and Opinions about Mental Illness (OMI) Scale, by Cohen \& Struening, [12]. The OMI 
was developed by Cohen and Struening, in 1962 and modified by Struening and Cohen in 1965. This scale consist of 51 items which are scored on a six point Likert scale ranging from 1 strongly disagree to 6 strongly agree; subdivided into 5 factors of (1) Authoritarianism, (2) Benevolence, (3) Social Restrictiveness, (4) Mental Hygiene Ideology and (5) Interpersonal etiology.

Cohen and Struening [13] discovered through factor analysis five opinion factors to which each item contributes specifically. High scores indicate support of the ideas represented by the corresponding factor.

Authoritarianism: This factor consists of 11 items and measures opinions about the mentally ill as an inferior class requiring coercive handling. High scores indicate a belief that the mentally ill are inferior to normal individuals.

Benevolence: this factor consists of 14 items which measures the pro-mental opinions, reflecting a kindly paternalistic view, a humanitarian, religious kindness towards the patients with mental illness. A higher score reflects an orientation toward care in general, not on a particular professional or scientific model.

Social Restrictiveness: This factor consists of 9 items that regard the mentally ill as a danger to society and suggests they should be restricted both during and after hospitalization. Low scores of this factor would be for the development of less restrictive environments for patients.

Mental Hygiene Ideology: This factor consists of 10 items that regard mental illness as an illness like any other and that a rational, professional approach to people with mental illnesses is crucial for adequate treatment. High scores indicate an optimistic view that mental illness is a disease like any other.

Interpersonal Etiology: This factor consists of 7 items, which measures the opinions that mental illness is caused by interpersonal experiences, especially parental deprivation during childhood. High scores suggest a respondent's opinion that mental health is subject to an individual's choices in life.

The low scores of factors $1,3, \& 5$ and high scores of factors $2 \& 4$ indicates favourable conditions towards persons with mental illness. The dependent variables for this study is the mean scores for each of the five OMI factors; while the independent variables of the participants were gender, age, year of study, religion, marital status, whether ever taught before coming to college, time completed secondary school and whether they grew up in a rural or an urban setting.

The OMI has several advantages which has contributed to an extensive use in several cultural settings thus: (1) when its items are closely scrutinized and compared with other scales it provide something patent to react to, (2) the coverage of the scale on salient issues, (3) its long history and therefore the possibility of assessing changes in opinions, and (4) the reliability and validity of the factor of OMI, [12].

This study hypnotized that no much difference in opinions of mental illness would be found between first years and second year students, gender, age, whether taught before or not, religion, marital status and whether participants grew up in a rural or urban setting.

\subsection{Data Management and Analysis}

The collected data for the study were analyzed using the Statistical Packages for the Social Software (SPSS), version 19.0. This analysis included descriptive statistics, t-test (independent sample), factor analysis of variance (MANOVA) and summary statistics. Descriptive statistics such as cross-tabulation, measures of central tendency (mean) and measures of variability (range and standard deviation) were used to describe the data. The t-test (a parametric statistics) was used to determine the significance difference, a probability level of $\mathrm{P}<0.05$. The Multiple Analysis of Variance (MANOVA); a statistical procedure use to assess group differences across multiple dependent variables simultaneously was used based on the independent variables of age, gender, year of study, religion, marital status, whether taught before or not.

\section{Results and Discussion}

\subsection{Results}

Out of the 2777 participants, 1466 (52.8\%) were female, $605(21.8 \%)$ were 20 years of age and under, $1664(59.9 \%)$ were between 21 and 25 years of age, and $508(18.3 \%)$ were over 25 years of age. $1274(45.9 \%)$ were first years, 597 $(21.5 \%)$ were married, $2(0.1 \%)$ were widowed, $21(0.8 \%)$ were divorced or separated and 2157 (77.7\%) were not married. Those who were Christians were 2665 (96.0\%), while those who were Muslims were $82(3.0 \%)$ and others were $29(1.0 \%)$. Those who had taught before coming to college were $1171(42.2 \%)$.

The summative score of Opinion on Mental Illness ranges between 51 and 306, with 51 a high score implying positive opinion. A score of less than 102 implies a negative opinion; 103-204 implies a moderate opinion while a score of 205 and above implies a positive opinion. The results among these participants indicate a moderate score across all the different socio-demographic factors.

Table 1. Summative scores for opinions about mental illness per demographic characteristics.

\begin{tabular}{|c|c|c|c|c|c|c|}
\hline \multirow{2}{*}{ Demographic Characteristics } & & \multicolumn{3}{|c|}{ Opinion on Mental Illness } & \multicolumn{2}{|l|}{ Tests } \\
\hline & & $\mathbf{n}$ & Mean & Stard.ard Deviation & $\mathbf{F}$ & Sig \\
\hline \multirow[t]{2}{*}{ Year of Study } & 1st Year & 1991 & 149.06 & 16.1 & \multirow{2}{*}{87.562} & \multirow{2}{*}{$.000 * *$} \\
\hline & 2nd Year & 1496 & 155.88 & 21.4 & & \\
\hline \multirow[t]{3}{*}{ Age Group } & $20 \&$ below & 609 & 153.25 & 18.88 & \multirow{3}{*}{0.704} & \multirow{3}{*}{0.495} \\
\hline & $21-25$ & 1658 & 152.8 & 19.74 & & \\
\hline & Over 25 & 510 & 151.89 & 19.21 & & \\
\hline Gender & Female & 1466 & 166.77 & 14.29 & 3835.063 & $.000 * *$ \\
\hline
\end{tabular}




\begin{tabular}{|c|c|c|c|c|c|c|}
\hline \multirow{2}{*}{ Demographic Characteristics } & & \multicolumn{3}{|c|}{ Opinion on Mental IIlness } & \multicolumn{2}{|l|}{ Tests } \\
\hline & & n & Mean & Stard.ard Deviation & $\mathbf{F}$ & Sig \\
\hline \multirow{3}{*}{ Religion } & Male & 1311 & 137.04 & 10.25 & \multirow{5}{*}{1.065} & \multirow{4}{*}{0.345} \\
\hline & Christian & 2665 & 152.84 & 19.49 & & \\
\hline & Muslim & 82 & 150.26 & 18.57 & & \\
\hline \multirow{4}{*}{ Marital Status } & Other & 29 & 149.69 & 16.5 & & \\
\hline & Married & 597 & 157.62 & 18.71 & & \multirow{4}{*}{$.000^{* *}$} \\
\hline & Widowed & 2 & 169 & 26.87 & \multirow{3}{*}{18.395} & \\
\hline & Divorced/Separated & 20 & 169.45 & 18.05 & & \\
\hline \multirow{3}{*}{ Ever Taught before coming to college } & Not Married & 2158 & 151.3 & 19.41 & & \\
\hline & Yes & 1173 & 160.42 & 20.11 & \multirow[t]{2}{*}{358.95} & \multirow{2}{*}{$.000^{* *}$} \\
\hline & No & 1606 & 147.11 & 16.83 & & \\
\hline
\end{tabular}

ANOVA was used to assess demographic variation in the OMI scale and significant differences were found in year of study, gender, marital status and whether ever taught before coming to college. No significance was indicated in age group and religious affiliation.

Further analysis using the five different OMI factors were conducted and a summary of the results are presented in Table 2 below.

Table 2. Presents the OMI Factors mean scores based on Demographic Characteristics.

\begin{tabular}{|c|c|c|c|c|c|c|}
\hline \multicolumn{2}{|c|}{$\begin{array}{l}\text { Demographic } \\
\text { Characteristics }\end{array}$} & \multicolumn{5}{|c|}{ Mean Scores of OMI Factors } \\
\hline Category & Factor & Authoritarianism & Benevolence & Social Restrictiveness & Mental Hygiene & Interpersonal Etiology \\
\hline \multirow{4}{*}{$\begin{array}{l}\text { Year of } \\
\text { study }\end{array}$} & Mean Scores & $11-66$ & $14-84$ & $6-54$ & $6-60$ & $7-42$ \\
\hline & $1^{\text {st }}$ year & 40.74 & 35.67 & 34.40 & 26.00 & 26.46 \\
\hline & $2^{\text {nd }}$ Year & 39.18 & 40.74 & 35.22 & 29.92 & 29.38 \\
\hline & & $\mathrm{F}=71.912, \mathrm{p}=0.000^{*}$ & $\mathrm{~F}=578.04, \mathrm{p}=0.00^{*}$ & $\mathrm{~F}=10.17, \mathrm{p}=0.001 *$ & $\mathrm{~F}=714.82, \mathrm{p}=0.000$ & $\mathrm{~F}=178.31, \mathrm{p}=0.000$ \\
\hline \multirow{4}{*}{$\begin{array}{l}\text { Age in } \\
\text { years }\end{array}$} & 20 & 40.03 & 37.88 & 34.17 & 27.67 & 27.09 \\
\hline & $21-25$ & 39.81 & 38.70 & 35.10 & 28.33 & 28.32 \\
\hline & 25 & 40.05 & 38.06 & 34.82 & 27.94 & 28.24 \\
\hline & & $\mathrm{F}=0.739 \mathrm{p}=0.478$ & $\mathrm{~F}=5.104, \mathrm{p}=0.006$ & $\mathrm{~F}=4.194, \mathrm{p}=0.015$ & $\mathrm{~F}=5.759 \mathrm{p}=0.003$ & $\mathrm{~F}=10.076 \mathrm{p}=0.000$ \\
\hline \multirow{3}{*}{ Gender } & Female & 37.91 & 40.46 & 30.08 & 29.18 & 23.88 \\
\hline & Male & 42.13 & 36.10 & 40.17 & 26.92 & 32.68 \\
\hline & & $\mathrm{F}=626.45 \mathrm{p}=0.00$ & $\mathrm{~F}=406.00 \mathrm{p}=0.00$ & $\mathrm{~F}=3428.68 \mathrm{p}=0.00$ & $\mathrm{~F}=203.29 \mathrm{p}=0.00$ & $\mathrm{~F}=3373.44 \mathrm{p}=0.00$ \\
\hline \multirow{4}{*}{ Religion } & Christian & 39.89 & 38.44 & 34.83 & 28.12 & 27.99 \\
\hline & Muslim & 39.95 & 37.10 & 35.01 & 27.88 & 28.76 \\
\hline & Other & 40.59 & 38.79 & 35.17 & 27.66 & 30.00 \\
\hline & & $F=0.29 p=0.75$ & $F=1.98 p=0.14$ & $\mathrm{~F}=0.07 \mathrm{p}=0.94$ & $F=0.29 p=0.75$ & $\mathrm{~F}=2.27 \mathrm{p}=0.10$ \\
\hline \multirow{5}{*}{$\begin{array}{l}\text { Marital } \\
\text { status }\end{array}$} & Married & 39.31 & 38.99 & 33.04 & 28.37 & 26.39 \\
\hline & Widowed & 35.00 & 42.50 & 30.00 & 29.00 & 26.50 \\
\hline & Div/sep & 38.95 & 40.25 & 32.20 & 27.50 & 25.15 \\
\hline & Unmarried & 40.08 & 38.22 & 35.37 & 28.05 & 28.52 \\
\hline & & $\mathrm{F}=6.590 \mathrm{p}=.001$ & $\mathrm{~F}=5.029 \mathrm{p}=.007$ & $\mathrm{~F}=30.355 \mathrm{p}=.000$ & $\mathrm{~F}=1.443 \mathrm{p}=.236$ & $\mathrm{~F}=33.201 \mathrm{p}=.000$ \\
\hline \multirow{3}{*}{$\begin{array}{l}\text { Ever taught } \\
\text { before }\end{array}$} & yes & 38.27 & 39.72 & 33.37 & 29.15 & 25.81 \\
\hline & no & 41.10 & 37.44 & 35.92 & 27.35 & 29.66 \\
\hline & & $\mathrm{F}=244.743$ p.000 & $\mathrm{F}=97.710 \mathrm{p}=.000$ & $\mathrm{~F}=99.887 \mathrm{p}=.000$ & $\mathrm{~F}=123.534 \mathrm{p}=.000$ & $\mathrm{~F}=317.493 \mathrm{p}=.000$ \\
\hline \multirow{6}{*}{$\begin{array}{l}\text { I grew up } \\
\text { in }\end{array}$} & Village & 39.94 & 38.40 & 34.93 & 28.11 & 28.10 \\
\hline & Town & 39.67 & 38.44 & 34.31 & 28.13 & 27.64 \\
\hline & & $\mathrm{F}=1.040 \mathrm{p}=.308$ & $\mathrm{~F}=.018 \mathrm{p}=.893$ & $\mathrm{~F}=2.970 \mathrm{p}=.085$ & $\mathrm{~F}=.013 \mathrm{p}=.911$ & $\mathrm{~F}=2.066 \mathrm{p}=.151$ \\
\hline & & Favourable $<22$ & Favourable $<56$ & Favourable $<18$ & Favourable $<40$ & Favourable $<14$ \\
\hline & & Neutral 22-43 & Neutral 28-56 & Neutral 19-36 & Neutral 21-40 & Neutral 14-28 \\
\hline & & Unfavourable $>43$ & Unfavourable $>28$ & Unfavourable $>36$ & Unfavourable $>20$ & Unfavourable $>28$ \\
\hline
\end{tabular}

In Factor I, authoritarianism, statistical significant differences were found in the following demographic characteristics, year of study $(p=0.000)$, gender $(p=0.000)$, marital status $(\mathrm{p}=0.001)$ and whether ever taught before $(\mathrm{p}=0.000)$. In factor II, Benevolence, statistical significant differences were indicated in year of study $(\mathrm{p}=0.000)$, gender $(p=0.000)$, and whether ever taught before coming to college $(p=0.000)$. In factor III Social Restrictiveness, significance was indicated in year of study (p-0.000), age group $(p=0.015)$, gender $(p=0.000)$ marital status $(p=0.000)$, and whether ever taught before coming to college $(p=0.000)$. In factor IV Mental Hygiene, significant differences were indicated in year of study $(\mathrm{p}=0.000)$, age group $(\mathrm{p}=0.003)$, gender ( $\mathrm{p}=0.000)$, and whether ever taught before coming to college. In factor $\mathrm{V}$ Interpersonal Etiology statistical significant differences were indicated in year of study $(p=0.000)$, gender $(p=0.000)$, marital status $(p=0.000)$ and whether ever taught before coming to college $(\mathrm{p}=0.000)$. 
Table 3. Correlation between OMI factors.

\begin{tabular}{|c|c|c|c|c|c|c|}
\hline \multicolumn{7}{|l|}{ Correlations } \\
\hline & & Authoritarianism & Benevolence & $\begin{array}{l}\text { Social } \\
\text { restrictiveness }\end{array}$ & Mental Hygiene & $\begin{array}{l}\text { Interpersonal } \\
\text { Etiology }\end{array}$ \\
\hline \multirow{3}{*}{ Authoritarianism } & Correlation & 1 & $-.270^{* *}$ & $.414^{* *}$ & $-.247^{* *}$ & $.425^{* *}$ \\
\hline & Sig. (2-tailed) & & .000 & .000 & .000 & .000 \\
\hline & $\mathrm{N}$ & 2777 & 2777 & 2777 & 2777 & 2777 \\
\hline \multirow{3}{*}{ Benevolence } & Correlation & $-.270^{* *}$ & 1 & $-.339^{* *}$ & $.353^{* *}$ & $-.277^{* *}$ \\
\hline & Sig. (2-tailed) & .000 & & .000 & .000 & .000 \\
\hline & $\mathrm{N}$ & 2777 & 2777 & 2777 & 2777 & 2777 \\
\hline \multirow{3}{*}{ Social restrictiveness } & Correlation & $.414^{* *}$ & $-.339^{* *}$ & 1 & $-.200^{* *}$ & $.630^{* *}$ \\
\hline & Sig. (2-tailed) & .000 & .000 & & .000 & .000 \\
\hline & $\mathrm{N}$ & 2777 & 2777 & 2777 & 2777 & 2777 \\
\hline \multirow{4}{*}{ Mental Hygiene } & Correlation & $-.247^{* *}$ & $.353^{* *}$ & $-.200^{* *}$ & 1 & $-.172^{* *}$ \\
\hline & Sig. (2-tailed) & .000 & .000 & .000 & & .000 \\
\hline & $\mathrm{N}$ & 2777 & 2777 & 2777 & 2777 & 2777 \\
\hline & Correlation & $.425^{* *}$ & $-.277^{* *}$ & $.630^{* *}$ & $-.172^{* *}$ & 1 \\
\hline \multirow[t]{2}{*}{ Interpersonal Etiology } & Sig. (2-tailed) & .000 & .000 & .000 & .000 & \\
\hline & $\mathrm{N}$ & 2777 & 2777 & 2777 & 2777 & 2777 \\
\hline
\end{tabular}

A correlation between the OMI factors showed a significant correlation between all the factors ( $p$-value $<0.05$ ). Negative correlations were observed between Authoritarianism and Benevolence $(\mathrm{R}=-0.27, \mathrm{p}=0.00)$, Authoritarianism and Mental Hygiene $(\mathrm{R}=-0.247, \mathrm{p}=0.00)$, Benevolence and Social Restrictiveness $(R=-0.339, p=0.00)$, Benevolence and Interpersonal etiology $(\mathrm{R}=-0.277, \mathrm{p}=0.00)$, Social Restrictiveness and Mental Hygiene $(R=-0.200$, $\mathrm{p}=0.00)$ and Mental Hygiene and Interpersonal etiology $(\mathrm{R}=$ $0.172, p=0.00)$. These implied as one increased the other decreased, and this was observed only in the negatively scored factors correlated with the positively scored factors. All the other correlations showed a significant positive correlation $(\mathrm{p}<0.05)$; table 3 .

\subsection{Discussion}

These results demonstrate a more negative (unfavourable) opinion about mental illness among these participants. This is in line with other studies in African contexts, [13] (in South Africa), [14] (West African Films), [15] among West African Communities and among Turkish population [16]. Medical doctors have also been found to hold negative opinions about mental illness, in Kenya [17], and India [18].

This study found that there was a significant difference in opinions about mental illness in gender, year of study, marital status and whether they ever taught before coming to college. Based on general summative scores, results indicated more favourable (positive) opinions among the female in the cumulative OMI score and the sub-scales of OMI. These results are in line with other studies among college students, in, India [18], between Hispanic and White in the USA [19], and the general population $[19,20,21,22]$. This variation has been associated with the need for females to look for treatment for mental illness compared to the males, who see it as a form of weakness, [22].

The second years indicated more positive (favourable) opinions about mental illness compared to the first years. This is consistent with other similar studies, [23, 24]. This variation has been speculated to have been contributed to by the curriculum coverage, of the second year students who has already covered psychology courses related to education in their studies. Significant variation indicated in marital status had no other study in literature to compare with globally; however, Aghukwa, [8] did not find any significant variation in this demographic characteristic among secondary school teachers in Nigeria. Those who had taught before indicated a more positive (favourable) opinions about mental illness compared to those who had not taught before. Although no study was found in literature, this was attributed to the learning they got from the experienced trained teachers in the schools they taught.

Measures of OMI Scale in Factor A (Authoritarianism) indicated that this population was inclined towards negative opinions. Significance was indicated in year of study, gender, marital status and whether they had ever taught before coming to college. The second years held opinions that are more favourable in this factor than the first years; this is in line with other studies among college students, [23, 24]. Female trainees held opinions that are more positive; this is consistent with other studies among college students and the general population globally, [18, 19, 22, 25]. This result suggests that females are less authoritarian in opinions about mental illness unlike males. This is attributed to the nurturance of females and way of socialization to take up gender roles, explained above. Significance indicated based on marital the higher scores among the not contributed status married. Although no study was found globally to compare these results this researcher has attributed this to the fact that married students are more likely to be more mature and through most cultural marital roles, and the institution of marital status they may have gone through an experience of meeting, caring and even discussing issues related to mentally ill in family. Those who had taught before coming to college indicated a more positive opinion in this factor. This result is attributed to the teaching experience that may have exposed them to mentally ill and exposure has been 
found to indicate more positive attitudes towards mentally ill among the general population and the health workers in general, $[15,26]$.

Benevolence indicated significance in year of study, age group, gender and whether they ever taught before coming to college. The second years had opinions that are more favourable in this variable than the first years; this is consistent with other studies among college students, [18]. Those who had higher age (21 and above years) had more favourable opinions in this factor than those who were 20 and below. This suggests that the older they were the more they held more positive opinions of an orientation of need of care of the mentally ill. This is consistent with findings of Niwako et al among Japanese general population [27], where they found that the older population is likely to be more benevolent. The female participants were found to hold more favourable benevolent opinions than the male. This is consistent with other studies, [27]. Those who reported to have ever had taught before coming to college were more benevolent than those who had not taught before. This is attributed to the experiences in teaching explained by Aghukwa [8] above.

Social Restrictiveness factor indicated significance in year of study, age, gender, marital statues and whether participants ever taught before coming to college. Significance indicated in the year of study was contributed by the high scores from the second years; who held opinions that individuals with mental illness are a threat to society and should be restricted to protect their families and the community at large. This finding is not consistent with other studies, [27, 28] and as expected from those already in the second year of study. Age in years significance was contributed by those who were older (21 and over years) who held more favourable opinions in this factor. This finding is consistent with other findings in West Africa [25]. The older the population was the less feelings of restricting the mentally ill and the less dangerous they felt about them Aghukwa [8]. Those who were not married indicated high scores in this factor compared to the other marital statuses. Being married may expose them to cultural caring and experience leading the married to have more favourable opinions in this factor. Those who had taught before coming to college held more favourable opinions in this factor. This is also contributed to the experience in teaching explained earlier above.

Mental Health Hygiene factor showed significance in year of study, age in years, gender and whether participants taught before coming to college. Those who were in second year of study, held opinions that the mentally ill were not different from others because they have a disease like any other, which needs treatment. This significance is attributed to the TTCs academic curriculum that exposed these participants to some education in mental illness, [27, 29]. Those who were older (21 years and above) indicated more positive opinions in this factor. This has been attributed to live experience as explained above. As expected the female participants were found to hold opinions that the mentally ill were not different from others, but had a disease similar to other diseases and the mentally ill needed medical treatment. This has been supported by other research, [19]. Those who had taught before coming to college held more favourable opinions in this factor. This has been attributed to teaching experience of the participants as explained above.

Interpersonal Etiology factor registered significance in year of study, age in years, gender, marital status, and whether ever taught before coming to college. Those who were in the first year of study unexpectedly indicated more favourable opinions in this factor. This has been attributed to the cultural beliefs held by communities in Africa, [29]. The older the participants were the more they held beliefs that individuals with mental illness were subject to that individuals choices in life. The female participants held more favourable opinions in this factor. This is in line with other studies, [30].

\section{Conclusion}

Unfavourable opinions about mental illness were found in this population, and it is recommended for an intervention in order to assist these participants improve attitudes towards professional help seeking for a mental illness. Its also recommended that the Ministry of Education, should include mental health in the trainees curriculum and further research should be done to ascertain the correlation between opinions of mental illness and attitudes towards professional help seeking.

\section{Acknowledgements}

We would like to acknowledge the African Mental Health Foundation (AMHF) and Bibwob Malel Psychological Consultants Ltd., (MICAP), for the generous contribution they gave in terms of accessing the Internet and the journals used in this document. This research was not funded.

\section{References}

[1] World Health Organization, (2004). A report of Mental Disorders, Effective Interventions and Policy Options, Department of Mental Health and Substance Abuse in collaboration with the Prevention Research Centre of the Universities of Nijwegen and Maastricht, Geneva.

[2] Knapp M. Funk M. Curran C. Prince M. Griggal \& McDaid D. (2006). Economic Barriers to better Mental Health Practice. Oxford University Press, London School of Economics and Political Science, UK.pg 157-170. Doi: 10.1093/heapol/czl003.

[3] Battaglia J., Conerdale J. H. \& Bushong C. P. Evaluation of mental illness awareness week program in public schools. American Journal of Psychiatry, 1990; 147 (3): 324-329. http://dx.doi.org/10.1176/ajp.147.3.324.

[4] Tinsley H. E. A., Brown M. T., de St. Aubin T. M. \& Lucek. J. Relationship between expectancies for a helping relationship; and tendency to seek help from a campus help provider. Journal of Counseling Psychology, 1984; 31(2): 149-160. 
[5] Nyavanga E. J., Ndetei D. M., Mathai M., \& Kuria M. W. Psychiatric Morbidity among Public Primary School Teachers at Mogotio Division, in Koibatek District. University of Nairobi, Faculty of Health sciences, School of Medicine. Department of Psychiatry, 2009. (unpublished).

[6] Moreno-Abril O., Luana-del-Castillo, J. D., Fernandez-Molina C., Jurado D., Gurpegui M. Laardelli-Claret P., and GalvezVargas R. Factors associated with psychiatric morbidity in Spanish Schoolteachers. Occupational Medicine, 2007; 57(3): 194-202.

[7] Pithers R. T., \& Soden R. Scottish and Australian teacher stress and strain: a comparative study. British Journal of Educational Psychology, 1998; 68(2): 269-279. Doi.1111/j.2044-8279.1998.tb01289.x.

[8] Aghukwa N. C. Secondary School Teachers Attitude to Mental Illness in Ogun State, Nigeria. African Journal of Psychiatry 2009; 1: 59-63. 30280-50731-1-PB\%20(1).

[9] Government of the Republic of Kenya, Ministry of Education. Summative Evaluation of Primary School teacher education. Kenya Institute of Education, 2010.

[10] American Psychiatric Association (2000). Diagnostic and Statistical Manual of Mental Disorders, (4 ${ }^{\text {th }}$ Edition Text Revision), Washington DC: Author.

[11] World Health Organization, (2015). Mental Helath Action Plan, 2013-2020.

[12] Cohen J. \& Struening E. L. Opinions about mental illness in the personnel of tow large mental hospitals. Journal of Abnormal Social Psychology, 1962; 64: 339-360. http://dx.doi.org/10.1037/h0045526.

[13] Hugo C. J., Bushoff D. E., Traut A., Zungu-Dirwawayi N., \& Stein D. J. Community attitudes toward and knowledge on Mental Illness in South Africa. Social Psychiatry and Psychiatric Epidemiology, 2003; 38 (12): 715-719.

[14] Aina O. F. Mental Illness and cultural issues in West. African films: Complications for orthodox psychiatric practice. Journal Med Ethics; Medical Humanities 2004; 30(1): 23-26. doi:10.1136/jmh.2003.000152.

[15] Adewuya A. O., Makanjuola R. O. A. Social distance towards people with mental illness amongst Nigerian university students. Social Psychiatry \& Psychiatric Epidemiology, 2005; 40(11): 865-868. Doi:10.1007/s00127-005-0965-3.

[16] Arkar H. \& Eker D. Effects of Psychiatric labels on attitudes towards mental illness in a Turkish sample. International Journal of Social Psychiatry, 1994; 40(3): 205-215. doi: 10.1177/002076409404000306.

[17] Ndetei D. M., Khasakhala L. I., Mutiso V., Mbwayo A. W. Knowledge, Attitude and Practice (KAP) of Mental Illness among staff in general medical facilities in Kenya: practice and policy. African Journal of Psychiatry, 2011; 14(3): 225 235. doi: http://dx.doi.org/10.4314/ajpsy.v14i3.6.

[18] Mahto R. K., Verma P. K., Verma A. N., Singh A.R., Chaudhury S. and Shantna K. Students' perception about mental illness. Industrial Psychiatry Journal, 2009; 18(2): 92 6 DOI: 10.4103/0972-6748.622676.

[19] Mori L. Panova A. Keo Z. S. Perceptions of mental illness and psychotherapy in a sample of Asian Hispanic and White College students. Journal of Psychiatry, Psychology and Mental Health 2007; 1(2); 1-13.

[20] Jackson D. and Hetherington L. Young Jamaicans' Attitudes Toward Mental Illness: Experimental And Demographic Factors Associated With Social Distance And Stigmatizing Opinions. Journal of Community Psychology, 2006; 34(5): 563-576. DOI: $10.1002 /$ jcop.20115.

[21] Loeng F. T. L., Zachar P. Gender and opinion about mental illness as predictors for attitudes towards seeking professional psychological help. British Journal of Guidance and $\begin{array}{llll}\text { Counseling 123-132. } & \end{array}$ DOI:10.1080/03069889908259720.

[22] Cotton, S. M., Wright A., Harris M. G., Jorm A. F., McGorry P.D. Influence of gender on mental health literacy in young Australians. Australian and New Zealand Journal of Psychiatry, 2006; 40(5): 790-796. DOI: 10.1111/j.14401614.2006.01885.x.

[23] Suradi Salim. Psychological Help seeking attitudes among Malaysian College and University Students. Prescodia Social and Behavioural Sciences, 2010; 5: 426-430. Doi: 10.1016/j.sbspro.2010.07.117.

[24] Chi Hakhoe Kanho. A comparison of nursing students' attitudes about mental illness according to year in college. Psychiatric Nursing 1989; 19(1): 81-91. PubMed.

[25] Adewuya A. O., \& Makanjuola R. O. Social /distance towards people with mental illness in southern Nigeria. Australian New Zealand Journal of Psychiatry, 2008; 42(5): 389-95.

[26] Lingeswaran, A. Psychiatric Curriculum and its Impact on the Attitude of Indian Undergraduate Medical Students and Interns. Indian Journal of Psychological Medicine 2010; 32(2): 119-127. DOI: 10.4103/0253-7176.78509.

[27] Niako, Y., Craig, P, Jannie, M. D., Kyler R, R. \& Kyley, A. D. Predictors of negative attitudes toward mental health services: A general population study in Japan. The European Journal of Psychiatry 2007/2011; 25(2): 101-110.

[28] Loeng F. T. L. and Lau A. S. L. Barriers to providing effective mental health services to Asian Americans. Mental Health Services Research, 2001; 3(4): 201-214. DOI.10.1023/A: 1013177014788

[29] Ani C. Kinanee J., Ola B. Psychological Distress among Trainee Teachers in Nigeria: association with religious practice. European Journal of Educational Studies 2011; 3(1): 163-172. SSN 1946-6331.

[30] Hanan Mohamed Mohamed Tork, Azza El Sayed AbdelFattah, Female Students' Attitude toward Mental Illness in Qassim University, KSA, American Journal of Nursing Science. Vol. 4, No. 3, 2015, pp. 50-56. doi: 10.11648/j.ajns.20150403.12. 